\title{
Securing a stable supply of critical raw metals
}

\section{— Efforts and issues for the securement of rare-earth resources -}

Tetsuichi TAKAGI

\author{
[Translation from Synthesiology, Vol.9, No.1, p.15-25 (2016)]
}

\begin{abstract}
In the early 21 st century, metal prices soared due to the economic development of newly industrialized countries. Moreover, a rareearth resource crisis occurred between 2009 and 2012 due to export restrictions imposed by China. Against this background, AIST set up a research base for critical metal resources, and established collaborative relationships with some foreign geological survey agencies (GS) from 2010. Furthermore, joint surveys were conducted with GS of South Africa, United States, Brazil, Mongolia, and others. While undertaking these surveys, we found a promising prospect for heavy rare-earth in South Africa. After the autumn of 2011, however, the prices of rare-earths collapsed, and the majority of rare-earth exploration/mining programs worldwide were put on hold. This sequence of events revealed the risks that accompany the development of critical metal resources. To mitigate the impact of future crises, AIST should continue research and development of rare-earth resources.
\end{abstract}

Keywords : Rare metal, mineral resource, rare-earths, stable supply, BRICS

\section{Introduction}

\subsection{What are rare metals?}

The metal resources are categorized into: common metals that are produced and consumed in large quantities such as iron and aluminum; base metals that are the basic materials of the industry; precious metals such as gold and silver; and rare metals that have low production volume and usage but are important in industry (Fig. 1). In Japan, the Ministry of Economy, Trade and Industry (METI) has designated 31 species of metals as rare metals. They are distinguished from other metal resources and policies are taken to ensure their stable supply. ${ }^{[1]}$ The rare earth elements are handled as a kind of metal among the rare metals, but in practice, rare earth is a general term for 17 metals including 15 lanthanide elements plus Scandium (Sc) and Yttrium (Y). The lanthanide elements with atomic weight lighter than Europium $(\mathrm{Eu})$ are called light rare earth elements, while those that are heavier are called heavy rare elements. The light rare earths are used in fluorescent materials, glass abrasive, oxygen scavengers for iron and steel, Ni-H batteries, oil refinement catalysts, and others. The heavy rare earths are mainly used in highperformance magnets.

\subsection{Rare metal shock}

The Japanese metal mining industry gradually contracted after the World War II due to the decrease and depletion of ore reserves. However, it declined rapidly since the 1980s due to increased yen value, increased cost of labor, pollution problems, and others. The major large-scale, high-

\begin{tabular}{|c|c|c|c|c|c|c|c|c|c|c|c|c|c|c|c|c|c|}
\hline $\mathbf{H}$ & & & & & & & & & & & & & & & & & $\mathrm{He}$ \\
\hline$\overline{\mathbf{L i}}$ & $\mathrm{Be}$ & & & & & & & & & & & $\bar{B}$ & $\bar{C}$ & $\overline{\mathbf{N}}$ & 0 & $\mathbf{F}$ & $\mathrm{Ne}$ \\
\hline $\mathbf{N a}$ & $\mathrm{Mg}$ & & & & & & & & & & & Al & $\mathbf{S i}$ & $\mathbf{P}$ & $\mathbf{S}$ & $\mathrm{Cl}$ & $\mathbf{A r}$ \\
\hline $\mathbf{K}$ & $\mathbf{C a}$ & Sc & $\mathrm{Ti}$ & $\mathbf{V}$ & $\mathrm{Cr}$ & $\mathrm{Mn}$ & $\mathrm{Fe}$ & $\mathrm{Co}$ & $\mathrm{Ni}$ & $\mathrm{Cu}$ & $\mathrm{Zn}$ & $\mathrm{Ga}$ & Ge & As & Se & $\mathrm{Br}$ & $\mathbf{K r}$ \\
\hline $\mathbf{R b}$ & $\mathrm{Sr}$ & $Y$ & $\mathrm{Zr}$ & $\mathbf{N b}$ & Mo & Tc & $\mathbf{R u}$ & $\mathbf{R h}$ & Pd & $\overline{A g}$ & $\mathbf{C d}$ & In & Sn & $\mathrm{Sb}$ & $\mathrm{Te}$ & $\bar{I}$ & $\mathrm{Xe}$ \\
\hline Cs & Ba & $* 1$ & Hf & Ta & W & $\mathbf{R e}$ & Os & Ir & $\mathrm{Pt}$ & $\mathbf{A u}$ & $\mathrm{Hg}$ & $\mathrm{TI}$ & $\mathrm{Pb}$ & $\mathrm{Bi}$ & Po & At & Rn \\
\hline Fr & $\mathbf{R a}$ & $* 2$ & Rf & $\mathrm{Db}$ & $\mathrm{Sg}$ & $\mathbf{B h}$ & Hs & $\mathbf{M t}$ & Ds & Rg & Cn & & Fl & & Lv & & \\
\hline & $* 1$ & $\overline{\mathrm{La}}$ & $\mathrm{Ce}$ & $\mathrm{Pr}$ & $\mathbf{N d}$ & $\mathrm{Pm}$ & $\mathrm{Sm}$ & $\mathbf{E u}$ & Gd & $\mathrm{Tb}$ & Dy & Ho & Er & $\mathrm{Tm}$ & $Y \mathbf{b}$ & $\mathrm{Lu}$ & \\
\hline & $* 2$ & Ac & Th & $\mathbf{P a}$ & $\mathbf{U}$ & $\mathrm{Np}$ & $\mathbf{P u}$ & Am & $\mathrm{Cm}$ & Bk & Cf & Es & Fm & Md & No & Lr & \\
\hline & $\mathrm{Ti}$ & Rare & et & & & & & $\mathrm{Cu}$ & Bas & 1106 & & & & $* 1$ & 17 & ides & \\
\hline & Dy & Rare & earth & art & rare & eta & & $\mathbf{A u}$ & Prec & us & etal & & & $* 2$ & (111 & & \\
\hline & $\mathrm{Fe}$ & Com & U & ta & & & & & & & & & & & & & \\
\hline
\end{tabular}

Fig. 1 General categorization of the metal resources

Institute for Geo-Resources and Environment, AIST Tsukuba Central 7, 1-1-1 Higashi, Tsukuba 305-8567, Japan E-mail: takagi-t@aist.go.jp

Original manuscript received January 9, 2015, Revisions received September 7, 2015, Accepted September 10, 2015 
grade mines terminated their activities (Kuroko mines of Hokuroku Region, Akita Pref. in 1993; Kamioka Mine, Gifu Pref. in 2001; and Toyoha Mine, Hokkaido in 2006), and the only mines still in operation are some gold mines (such as Hishikari Mine, Kagoshima Pref.). Today, the Japanese industries are dependent totally on imported metal resources, and maintaining stable supply is a vital issue. Fortunately, from the 1980s to the beginning of 2000s, the prices of metal resources were relatively stable, and they could be imported liberally by Japan's economic strength. During this time, a sense of crisis toward the procurement of metal resources was not necessarily high for both the Government and private companies.
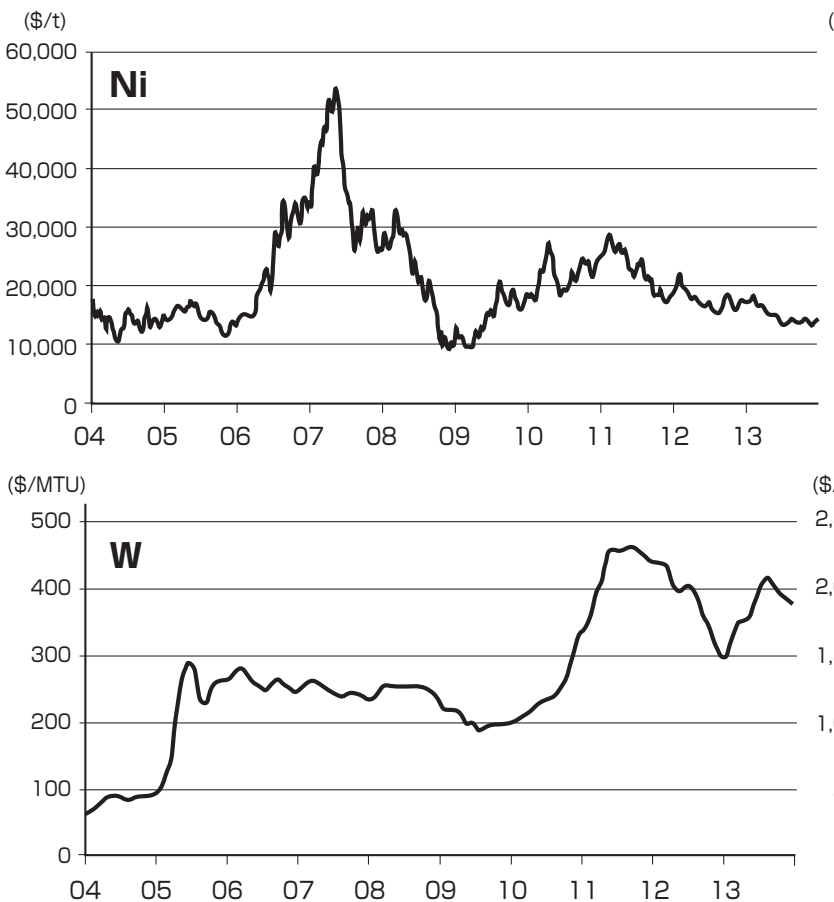

The prices of nonferrous metal resources that used to be stable rose rapidly from about 2004. This was the start of the "rare metal shock" (Figs. 2 and 3). It was caused mainly because the increasing consumption of metal resources by the emerging industrial countries such as BRICS surpassed the buffer capacity of the market. The price increase stopped temporarily after the Lehman Shock, but it started to rise again and continues to the present. The competition for nonferrous metal resources such as rare metals and base metals has become global, and it has passed beyond the capacity of private companies and has become an international matter. The procurement of mineral resources now requires the combined forces of politics, diplomacy, and

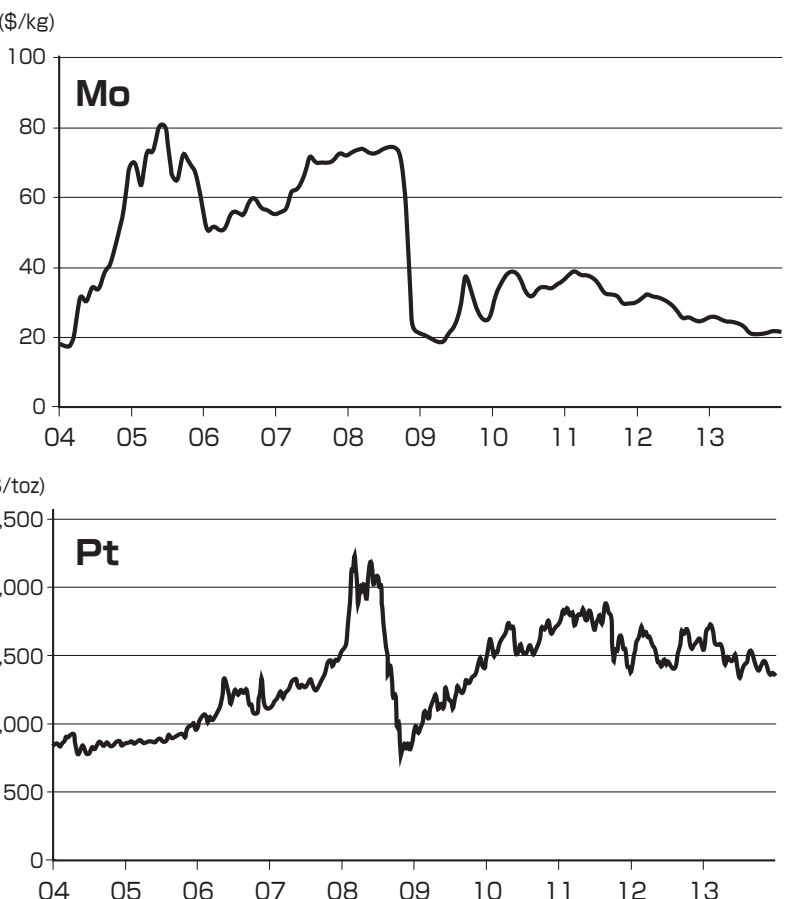

Fig. 2 Transition of the prices of major rare metals (compiled by METI based on the prices of the London Metal Exchange)

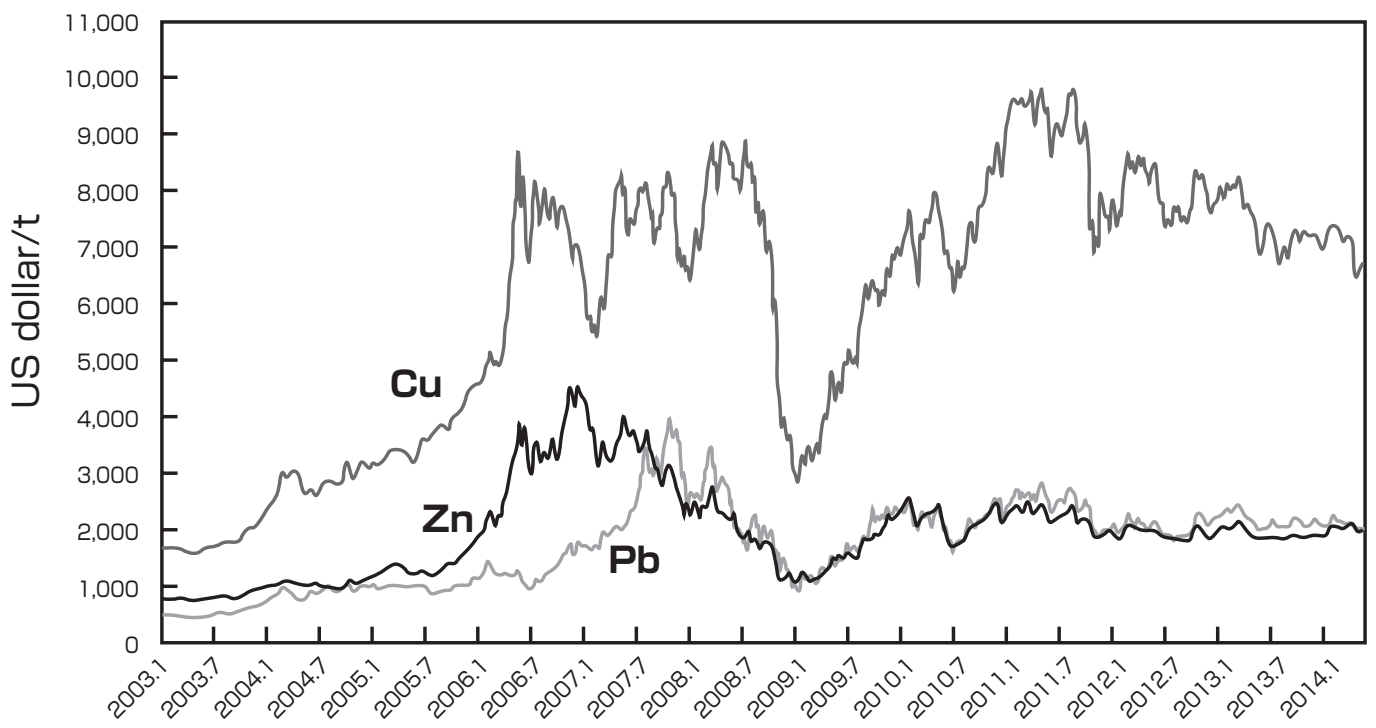

Fig. 3 Transition of the prices of base metals (copper, lead, and zinc) (London Metal Exchange) 
science and technology, not just economic power. METI set up the "Rare Metal Procurement Strategy" and the Government came to the forefront to take active measures for resource procurement strategies.

\section{Objective of the rare metal resource research}

\subsection{Rare metal resource research}

The research of rare metals can be roughly divided into materials science and earth science. In the former, the objective is the R\&D for high-performance materials using rare metals, reduction of rare metal use, alternative materials, and recycling. In the latter, the objective is the exploration of rare metal resource and resource evaluation (the development of mineral processing and refining technologies partly spans across both fields). Since AIST engages in general research of rare metals, a rare metal task force was set up in 2006, and research was conducted on materials science and earth science like two wheels of a car. ${ }^{[3]}$ In this paper, the earth science research of rare metals will be addressed as the "rare metal resource research."

\subsection{Characteristic of rare metal resources}

Mineral resource development generally requires about 10 to 15 years from exploration to commercial mining. Since large cost is necessary for various surveys and tests, the project cannot be continued unless there is certainty of profit for the exploitation. There are many cases where the development plans were stopped due to the issues of insufficient minable reserves or low grade, as well as due to problems of costs needed for mining, processing, and refining. The international market is well established for nonferrous metals such as base metals and precious metals, and stable profits can be gained. Also, refineries are in operation in Japan for copper and zinc, and the sales volume is stable since there is a need to continuously supply the ore to the furnace. Therefore, the major mining companies and general trading corporations carry the burden of development risks, and engage in active investment and development. On the other hand, although essential in advanced industries, only small amount of rare metals is mined and used, and the profits by sales and purchases are small. Also, the species of required rare metals may change in a short period of time due to the advances in technology. There is no international market established for most rare metals, and the prices shift greatly due to political and economic reasons including speculation, war, mine strikes, or protectionism. Due to high risks, the resource development of rare metals is often done by venture companies or junior mining companies (companies that specialize in exploration with no large-scale capital such as mines). Many rare metal deposits are "nonconventional types" where the occurrence is totally different from the base metal deposits, and advanced geological and mineral processing knowledge are required for their development. To procure the rare metal resources with certainty, the resource potential evaluation at the early stage of development must be done by public institutions (such as geological surveys and universities) instead of private companies, to determine the prospective cases to reduce the investment risks as much as possible. Compared with other engineering fields at AIST, rare metal resource research is characterized by the fact that the cycle time of R\&D is extremely long, and the risk factors spread widely beyond technological development. Therefore, long-term continuous $R \& D$ is necessary.

\section{Strategy for rare metal resource procurement}

As mentioned before, rare earths are part of rare metals, but in the past recent years, the procurement strategy for rare earth resources in Japan was almost equivalent to the procurement strategy for rare metal resources. Therefore, in this chapter, I shall discuss the strategy taken by AIST for rare earths.

\subsection{Rare earth crisis}

The rare earths were mainly produced in the placer deposits of India until the $1980 \mathrm{~s}$, but when the demand increased in the 1990s, they were produced mainly by the Mountain Pass Mine in the USA. From the end of 1990s to the beginning of 2000 s, the production volume from China increased rapidly, and China dominated over $90 \%$ of the share in the world market through its low price strategy. Not only was the Mountain Pass Mine unable to compete with China in terms of cost, but also the environmental pollution problem by wastewater drainage forced the mine to close in 2002. China gradually started to regulate export by setting the ceiling on rare earths from about 2007, and the supply risk started to become apparent. However, from about 2009 when the effect of Lehman Shock settled, the demand-supply balance was toppled due to the tightening of the export ceiling, and the price soared from the latter half of 2010. Since the Senkaku Island incident in September 2010, when a Chinese fishing boat collided with the Japan Coast Guard ship, the rare earth export from China to Japan was halted, and the "rare earth crisis" occurred as the Japanese industries faced a serious lack of rare earth supply. The rare earths marked the highest price in history on August 2011 (Fig. 4).

\subsection{Scenario for rare earth resource development}

Rare earth resource development starts with the discovery of mineral prospects (outcrop where the concentration of ore minerals can be found on the ground surface) as in base metals and precious metals. A mineral prospect is studied by specialists to clarify its occurrence and extent by ground surface survey, and confirmation is made on whether it is an ore deposit (place where the mineral is concentrated at a certain amount). In the following reconnaissance survey, the extent of hydrothermally altered zone and the hydrothermal origin are studied if it is a hydrothermal deposit, or the distribution and thickness of the horizon in which the heavy 
minerals are concentrated are studied if it is a placer deposit. This allows the evaluation of the size and reserve of the ore. In the case of rare earth resources, an initial mineral processing test is likely to be done at this stage. This is because unless the ore containing rare earths can be readily separated and extracted, development will be difficult even if the rare earth content (grade) is high. In many cases, a company or geological survey may execute the survey up to this stage.

If it is determined that the deposit is promising, close investigation follows. This includes drilling surveys and geophysical exploration that are conducted to determine the amount of reserve. Moreover, highly dense drilling (several tens to several thousands of holes) and test mining are done to estimate the minable reserve. The drillings and geophysical exploration are expensive, and therefore, in Japan, when the interests of the Japanese companies are involved, the normal practice is for the Japan Oil, Gas and Metals National Corporation (JOGMEC) to conduct such surveys solely or jointly with private companies, and then hand the project over completely to the companies at an appropriate stage. When the main developing companies are determined and the specific development plans for the mine are drawn, the environmental impact assessment and infrastructure development are done. Only after all these phases are cleared, the mine is opened. In the case of rare metal resources including rare earths, the development risk is greater than other nonferrous metals, and in many cases, support by JOGMEC or the Japan Bank for International Cooperation (JBIC) may be necessary after the mine starts operation.

\subsection{Requirements for rare earth resource development}

Currently, because China dominates most of the rare earth resource supply, we must develop or redevelop rare earth deposits outside China to ensure supply of new raw materials. The requirements include the following items.

Grade: To be competitive against the Chinese rare earth ore,

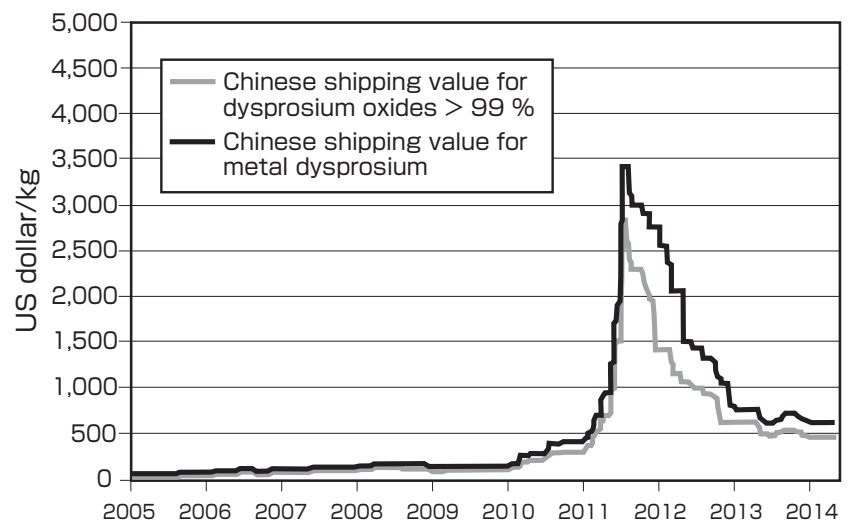

ore that contains abundant light rare earths must have $4 \%$ or more of total rare earth quantity (in terms of oxide), and ore that contains heavy rare earths must have $1 \%$ or more.

Rare earths containing minerals: Readily soluble carbonates (bastnäsite, etc.) or phosphates (monazite, xenotime, etc.) are desirable. Refractory minerals (phosphates containing aluminum, niobium minerals, zircon, etc.) are expensive to dissolve. Also, processing is difficult unless the average grain size is $100 \mu \mathrm{m}$ or more.

Reserve: Several tens of thousands of tonnes or more for total rare earths.

Mining method: In principle, it should be open-pit mining.

Radioactive material: High concentration of thorium is often found in monazite. In the case where there is high volume of waste materials containing thorium, these must be stored or disposed by burial according to the standards ${ }^{[4]}$ of the International Atomic Energy Agency (IAEA). Although there is no definite threshold, less than $1,000 \mathrm{ppm}$ for unprocessed ore (raw ore) is desirable.

Social environment: Infrastructures such as roads and railways must be available. There must be sound security enforcement and mining laws.

In the case where AIST conducts the exploration of rare earth deposits, whether the target mineral occurrence fulfills the above requirements will be checked through various surveys and analyses. Therefore, it is important to request information to the geological surveys of the respective countries beforehand, and carefully plan the survey strategy.

\section{Effort on the rare earth resource research}

In this chapter, response to the aforementioned rare earth crisis will be described as an example in which AIST contributed to the Government's rare metal resource

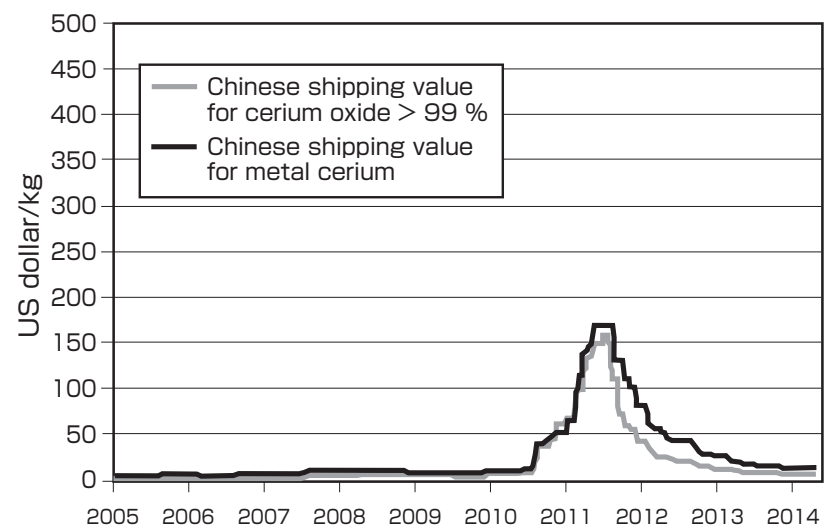

Fig. 4 Transition of the prices of dysprosium (heavy rare earth) and cerium (light rare earth) (compiled from the material in Metal Pages Website) 
procurement strategy.

\subsection{Establishment of the research base for rare metal and rare earth resources}

With the occurrence of the rare earth crisis, the Japanese Government set aside a budget for measures to procure rare earth resources in the supplementary budget for fiscal years 2010 and 2011, and provided large funds to AIST for a subcontract project of the Agency of Natural Resources and Energy (actual execution of the fund was for FY 2011 and 2012). Prior to this, in autumn 2010, the Agency requested AIST to establish a research base for rare metal and rare earth resources. However, the mineral resource research at AIST had been shrinking since the days of the former Agency of Industrial Science and Technology, and the Institute for Environmental Management Technology (part of the former National Institute for Resources and Environment) that was in charge of the development of mineral processing and refining technologies had shifted completely to recycling technology research. Even at the Institute for Geo-Resources and Environment (GREEN), which engages in ore genesis research and exploration technology development, there was only one research group, reduced from the four sections at the old Geological Survey of Japan. The organization was too weak to form a research base. Therefore, the GREEN would conduct the rare earth deposit exploration and initial processing tests, while the Tohoku University would be in charge of the full development of the mineral processing and metallurgical technologies, and the aforementioned supplementary budget was used to start a new base. The Strategic Urban Mining Research Base (SURE) was established in the Institute for Environmental Management Technology in 2014, and has become the center of recycling R\&D for rare metals. ${ }^{[5]}$

The GREEN introduced the facilities for ore and mineral analyses and mineral processing tests during the two years from 2011 to 2012 to organize the research base. ${ }^{[6]}$ The

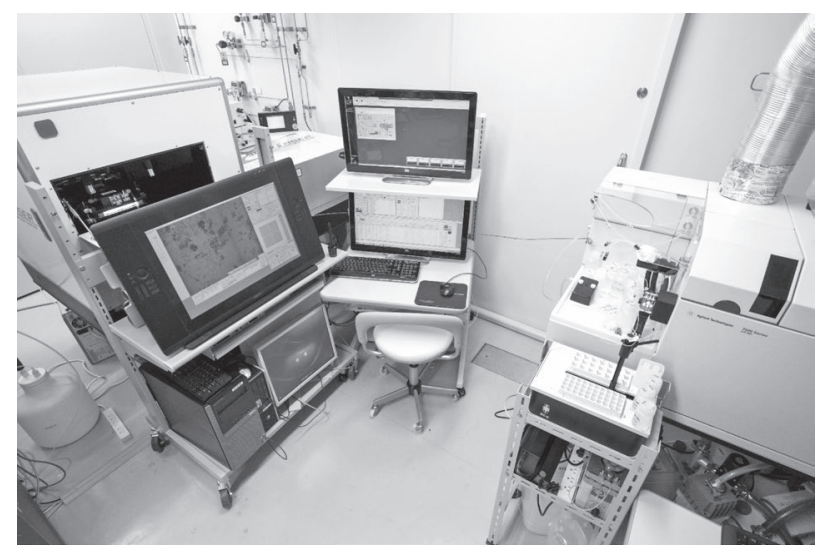

Fig. 5 Laser ablation inductively coupled plasma mass spectrometer (LA-ICPMS). Laser light source by Cyber Laser Inc., ICPMS by Agilent Technologies Japan, Ltd., and other parts were assembled in house. facility for analyzing minerals and rocks was available at the GREEN, however, metal ore has extreme concentration of certain elements compared to ordinary rocks, and the rare earth ore tended to have high concentration of radioactive elements such as thorium. Therefore, to conduct full rare metal and rare earth resource research, it was necessary to construct a new experimental facility separate from the old facilities, to avoid contamination and to properly dispose the wastewater and dust generated in the experiment. One of the newly introduced devices that should be particularly mentioned is the laser ablation inductively coupled plasma mass spectrometer (LA-ICPMS). ${ }^{[7]}$ The LA-ICPMS is a device that concentrates and irradiates laser beams to a solid that is the analysis subject, takes the evaporated surface materials into the ICPMS as aerosol along with high-pure argon gas, and conducts the chemical analysis (Fig. 5). The process does not require pretreatment of the sample, and allows local analysis at high precision. In the analysis of rare earth ore using this device, there is no problem of undissolved samples that could not be avoided in the conventional acid dissolution method, and the analysis can be done quickly in two minutes per sample. ${ }^{[8]}$ The device at GREEN was improved and new functions were added for ore analysis. It has been used for analysis of several hundred pieces of ore from a dozen countries, and contributed greatly to rare metal resource research. The next device that should be mentioned is the mineral liberation analyzer (MLA) (Fig. 6). The MLA is a device that combines a regular scanning electron microscope and powerful image analysis software, and it has the function of calculating and displaying statistical data such as mineral ratio, grain size, and composite ratio of the ore or mineral powder from a single sample in a few hours. This device was also used to analyze several tens of rare metal ore samples, and greatly contributed to the formulation of the evaluation and processing methods. Also, sensitive high-resolution ion microprobe (SHRIMP) (Fig. 7) and highvoltage pulse selective crushing equipment (manufactured by SELFRAG AG) have been introduced and the results are being produced. As mentioned earlier, the mineral processing lab is equipped with wastewater and dust disposal facilities.

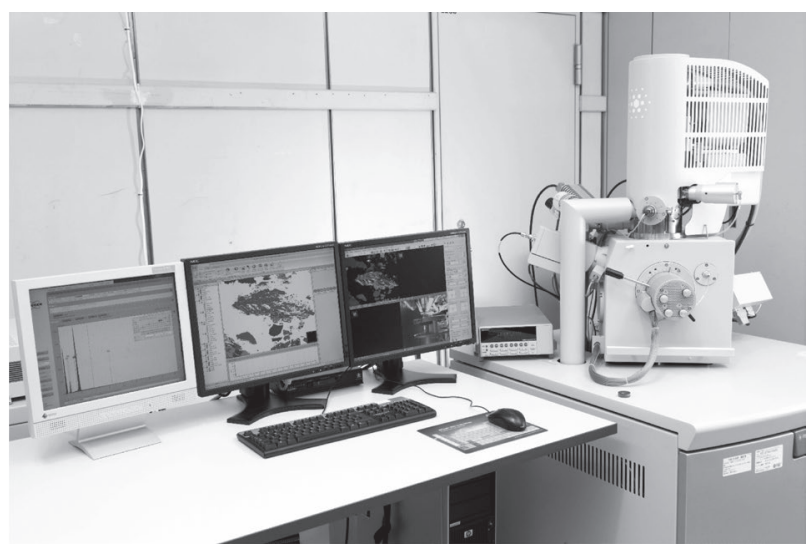

Fig. 6 Mineral liberation analyzer (MLA) by FEI 
For wastewater, by a process using the vacuum distillation volume reduction device, the suspension water containing heavy metals and radioactive materials is prevented from escaping outside the lab.

\subsection{Building research cooperation framework with overseas geological surveys}

In the measures against rare earth crisis, the building of research cooperation framework with overseas geological surveys is essential in terms of organizing the research promotion environment. The following three can be given as the reasons why this is very important.

1) Collection of highly reliable resource information of the resource-producing countries: When conducting overseas resource survey, it is necessary to narrow down the prospective areas by obtaining preliminary information from official geological survey of the country.

2) Ensuring safety during overseas survey: Cooperation of the official geological survey is necessary to safely conduct survey in accordance to the local security and natural environment.

3) Contribution to resource diplomacy: By showing that we are cooperating with the resource-producing countries to others, we can appeal that Japan is strategically working on the measures to procure resources. By doing so, this may prevent other resource-producing countries from taking extreme resource policies such as banning export of rare earths to Japan.

The partners of international research cooperation are assumed to be countries with high potential of prospective rare earth deposits. However, selection is based on the comprehensive examination based on the METI policy, request of local government organizations, past record of cooperation, security and political situation, and others. The history of major international research cooperation will be presented below.

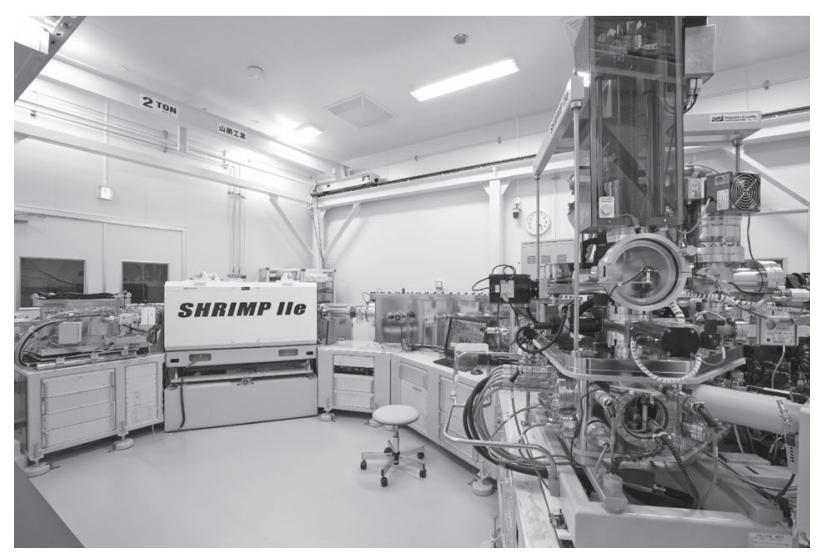

Fig. 7 Sensitive high-resolution ion micro probe (SHRIMP) by Australian Scientific Instruments
USA: Since the occurrence of the rare earth crisis, the Japanese Government became active in the attempt to solve the problem, with focus on the Japan-USA cooperation. In November 2010, the Japan-US Rare Earth Roundtable was held at the Lawrence Livermore National Laboratory, and opinions were exchanged by the rare earth researchers of Japan and the US. AIST (researchers of resource saving, recycling, and resource exploration) participated in this roundtable along with the specialists of METI, JOGMEC, New Energy and Industrial Technology Development Organization (NEDO), and major universities. In January 2011, the Japan-US Rare Earth Conference was held at the US Department of Energy. The personnel in charge from various ministries and agencies of Japan and JOGMEC attended this conference, while from AIST, only the author attended due to a policy decision of giving priority to cooperation in the resource exploration field, and future Japan-US research cooperation was discussed. At this conference, the research cooperation on rare metal resource was agreed between AIST and the US Geological Survey (USGS). After nonofficial meetings, a memorandum of research cooperation was formally signed between AIST and USGS in San Francisco in December 2011. On-site surveys of rare earth mineral occurrences were done in the southern part of Alaska in August 2011, eastern Missouri in November 2012, southern California and central Georgia in October 2014, and on-site surveys were also planned for FY 2015.

Republic of South Africa: South Africa is a mining giant that produces abundant rare metals such as the platinum metal groups and chromium. A memorandum for research cooperation was signed by three parties, Council for Geoscience (CGS) of South Africa, JOGMEC, and AIST in 2007, before the rare earth crisis. Ever since, survey research (will be explained later) has been done actively. In the agreement at the Japan-South Africa Conference of Ministers of Mining held in 2013, the promotion of this research cooperation was stated clearly. In March 2014, the research cooperation memorandum between AIST and CGS was updated, and continues to be in effect today.

Mongolia: Since the times of the Agency of Industrial Science and Technology, there is a long history of research cooperation with Mongolia in the mineral resource field, through the projects of the International Transfer of Industrial Technology (ITIT) and the Japan International Cooperation Agency (JICA), and exchange at researcher level has continued after the establishment of AIST. In October 2010, faced with the rare earth crisis, a research cooperation memorandum was formally signed by three parties, AIST, JOGMEC, and the Mineral Resources Authority of Mongolia (MRAM). On-site survey of the rare earth mineral occurrences was conducted in the southern Gobi region in 2010, and with the cooperation of private companies of Mongolia, surveys were done in the western region of 
Mongolia in 2011 2012. Currently, the mining districts are being reviewed due to the changes in mining laws of Mongolia, and the research is temporarily suspended until the rare metal resource policy of Mongolia is settled.

Federative Republic of Brazil: In the joint seminar of AIST, Companhia de Pesquisa de Recursos Minerais (CPRM), and Departamento Nacional de Produção Mineral (DNPM) held at the CPRM headquarters in November 2009, the research cooperation was agreed in several earth science fields including the rare earth resource research. Later, after Japan-Brazil Joint Committee Meeting on Cooperation in Science and Technology in December 2010 and other informal meetings, a research cooperation memorandum was officially signed between AIST and DNPM in December 2012. The author presented a lecture on the Japanese rare earth resource policy at the hearing of the Federal Senate, National Congress of Brazil in June 2013. On-site surveys of the rare earth mineral occurrences were conducted in the southern part of the State of Goiás and central southern area of the State of Minas Gerais in 2013, and in northern Goiás in February 2014.

Other countries: The organizations with which research cooperation memorandums were signed for rare metal and rare earth resources include: the Department of Geological Survey and Mineral Exploration (DGSE), Myanmar; Korea Institute of Geoscience and Mineral Resources (KIGAM); and Department of Mineral Resources (DMR), Thailand. Regular human resource exchange is done with these institutions. Although research cooperation memorandums have not been signed, we have research exchange with: Geologian tutkimuskeskus (GTK) of Finland; Maden Tetkik ve Arama Genel Müdürlüğü (MTA: General Directorate of the Mineral Research and Exploration), Turkey; Geoscience Australia; and several other institutions.

\subsection{Survey of rare earth mineral deposits and occurrences - The case of South Africa}

In this subchapter, I describe the history and the future prospect in South Africa where the survey research has reached the advanced stage.

Discovery of mineral occurrences: In the northeastern region of South Africa including the capital city Pretoria, there is a giant exposure of Bushveld Complex that spans $460 \mathrm{~km}$ east-west and $250 \mathrm{~km}$ south-north. This rock body is composed of rocks that were formed as the magma cooled and solidified deep underground two billion years ago, and the platinum group elements and chromium that are the main rare metal resources of South Africa are produced from the deposits of the Bushveld Complex. There are several fluorite $\left(\mathrm{CaF}_{2}\right)$ deposits distributed in this rock body region, and some are actively mined as the raw material for fluoride. It is known worldwide that the fluorite deposits are often accompanied by high concentration of rare earths, and the mineral occurrences of rare earths were confirmed in the reconnaissance survey before 2008 at the fluorite mines that were in operation in the area. However, most of the operating mines were managed by foreign companies operated by white people, and the survey research under South Africa's Black Economic Empowerment (BEE) policy was difficult. In the on-site survey conducted jointly by AIST and CGS in September 2009, a rare earth prospective area was found near the old fluorite mine in the central area of the Bushveld Complex. This occurrence was in an undeveloped region, but the CGS researchers had detected the alteration zone in the ground surface accompanying the exploration of the fluorite deposit. As a result of analysis conducted at AIST, it was confirmed that this prospect could be a promising deposit abundant with heavy rare earths.

Application for the mine exploration district: During 2009 to 2010, the rare earth prices were soaring, and it was necessary to protect this rare earth deposit from other exploration companies. Therefore, CGS applied for the mine exploration district to the Ministry of Mineral Resources through the African Exploration, Mining and Finance Corporation (AEMFC). Since the deposit region was state-owned land and all land managers were native people, it was possible to conduct on-site survey without trouble.

Execution of exploratory drilling: From the result of the radioactive exploration conducted by CGS, the extent of the deposit was narrowed down, and five shallow exploratory drilling was done in FY 2012, and three in FY 2013 (Fig. 8). As

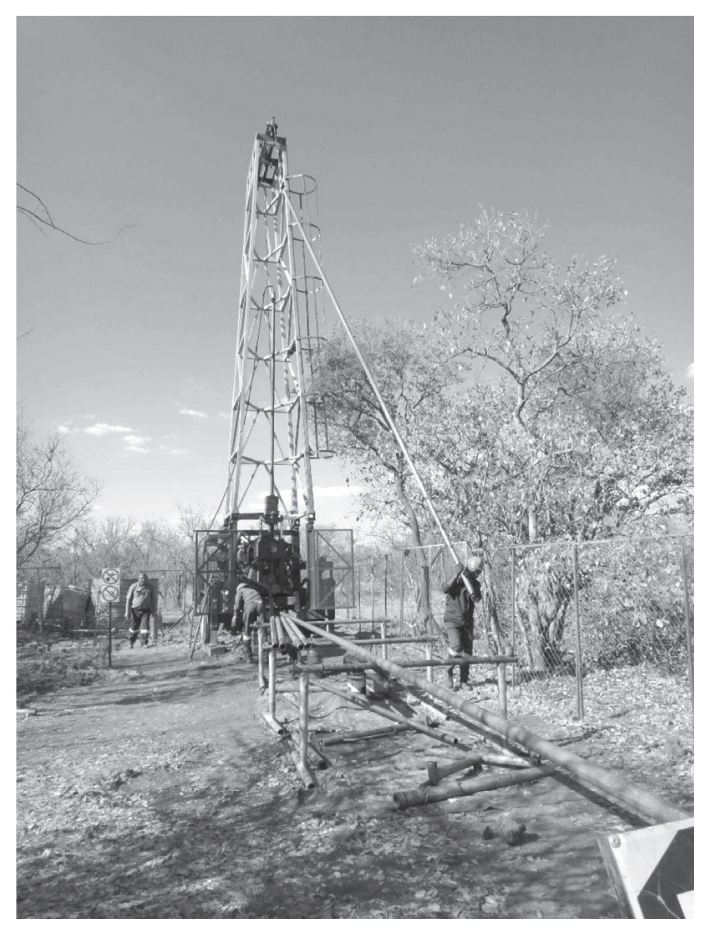

Fig. 8 Shallow exploratory drilling conducted in South Africa (August 2013) 
a result, it became clear that the rare earth grade was relatively high in the lateritic weathered crust dozens of meters from ground surface, and similar grade was found in the pegmatitic zone in the concealed unweathered plutonic rock. The average rare earth grade is around $1 \%$ in terms of oxide, and has the characteristic of containing abundant yttrium and heavy rare earths. The rare earth containing minerals are phosphates that are relatively easy to dissolve, and the thorium content is less than $100 \mathrm{ppm}$, that is slightly higher than ordinary rocks. Therefore, it was determined that development would be possible from the weathered crust that was easy to mine.

Mineral processing test: For the development of this deposit, the essential condition is to establish the technologies to extract the rare earth containing minerals in the weathered crust and to make concentrates. This is because if the weathered crust rocks are dissolved in acid or alkali, large amount of chemicals will be necessary, and this will not be cost effective. In FY 2013-2014, several tens of kg of samples were brought to AIST from the site, and emphasis was shifted to a labscale processing test. In FY 2015, we asked cooperation from Waseda University and Mintek of South Africa, and plan to accelerating the mineral processing test to improve the rare earth quality of the concentrates.

Future prospect: In December 2013, part of the survey results of this rare earth deposit was disclosed at a hearing held in Tokyo, but there was no Japanese company that showed interest at that point. In the future, after obtaining certain results in the mineral processing test, we plan to organize the total results and disclose this information again to the companies and JOGMEC. Also, it is likely that we will add more survey research necessary to increase the materials on which decisions can be made. In any case, there is a limit in continuing the survey research paid by the funds of AIST and CGS alone, and external (JOGMEC, private companies, etc.) funding is necessary to advance the development of this deposit. If it becomes possible to produce heavy rare earths from this deposit, we will have a new supplier other than China. Even if the production volume is small, this will give a sense of security to the market that heavy rare earths can be obtained without the country risk of China, and this is expected to help stabilize the prices.

\subsection{Construction of the rare earth resource database}

When the government or private companies create a strategy for rare earth resource procurement, it is necessary to understand the distribution, size, properties, and others of the rare earth resources around the world. If it becomes apparent that the deposit of rare earth resources is concentrated in a certain country, it becomes possible to convince that country to export the products at appropriate prices as a responsibility to the international community. Therefore, the USGS annually discloses various mineral resource information such as the Mineral Commodity Summaries on the website. ${ }^{[9]}$ In the case of rare earth resources, worldwide exploration and development have been conducted using the database by Orris and $\mathrm{Grauch}^{[10]}$ published in 2002. However, 12 years have passed and with the occurrence of the rare earth crisis, the time has come to totally review the database for rare earth resources and to recreate the strategy for resource procurement. Therefore, AIST is working on the rare earth resource database jointly with USGS, and the first results will be published in 2016.

The material flow analysis and demand-supply projection for rare earths are being conducted concurrently, and results have been obtained. ${ }^{[11][12]}$ The objective of this research is to analyze the flow from import, commercialization in Japanese industry, to export, disposal, or recycling of rare earths, as well as to forecast the shift in supply and demand based on the future prices and technological trends, and to contribute to the strategic planning for resource exploration, resource saving, and recycling.

\section{Issues after the rare earth crisis}

\subsection{Crash of rare earth prices}

The prices of rare earths reached the peak in August 2011, and dropped to $1 / 30$ for cerium and $1 / 4$ for dysprosium in 2013 (Fig. 4). This was due to the fact that China released the stock that was built up due to the export ban, and the Japanese companies that used rare earths switched to alternative products and actively reduced the amount of rare earths used. However, due to the crash of rare earth prices, about 100 rare earth resource development programs that were being conducted around the world were almost all delayed, suspended, or terminated, except for the Mountain Pass Mine in USA and the Mt. Weld Mine in Australia. As mentioned earlier, a period of about 10 to 15 years is required for mineral resource development, and it was difficult to develop new mines in a time period of about four years within which the rare earth crisis became apparent and the prices crashed. Also, Molycorp Minerals, the operator of the Mountain Pass Mine that continued operation for a while after the rare earth crisis, applied for "Chapter 11" bankruptcy reorganization on June 2015. This event reminded the mining people how high the risk is for rare metal resource development.

\subsection{Role of AIST in full-scale research}

Although the rare earth crisis settled down, the diversification of rare earth supply sources did not occur, and the domination by China, just like before the crisis, continues to the present. Rare metals, similarly to rare earths, for which China dominates $80 \%$ as the supplier, includes tungsten, antimony, and others (Fig. 9). Depending on the international situation, China may again play the resource card, and the potential for crisis has not decreased. The rare earth crisis is not a transitory event. It will be too late if measures are taken at the occurrence of the next rare earth crisis. However, as mentioned in Chapter 2, rare metal and rare earth resource 
development is a high risk for private companies, and there are limits to preliminary preparation and investment. Currently, AIST, in collaboration with other organizations (Agency of Natural Resources and Energy, JOGMEC, overseas geological surveys, universities, etc.), is the only research institution that is capable of continuous and systematic information collection, survey research, and human resource training for rare metal and rare earth resources. The execution of R\&D with mediumto long-term vision that is not affected by immediate resource demand, in preparation of the second and third rare earth crises that will certainly occur in the future, is full-scale research that AIST should take on (Fig. 10). As of 2015, the attention toward and the sense of crisis for mineral resource supply has decreased due to the lowered prices of resources arising from the economic deceleration of China. However, lowered resource prices lead to selective mining at high-grade zones that yield profit, which brings about shortened lifespan of the mines and depletion of the reserves. In preparation for the reaction against the lowered resource prices that is sure to happen in the future, AIST has the responsibility to execute full-scale research.

\section{Acknowledgements}

I am thankful to Yasushi Watanabe (Akita University, former Group Leader, Mineral Resources Research Group) and the people of Mineral Resources Research Group, GREEN who are involved in this research. I am also sincerely grateful to the people of the Mineral Resources Section, Agency of Natural Resources and Energy and the Metal Resources Development Headquarter, JOGMEC.

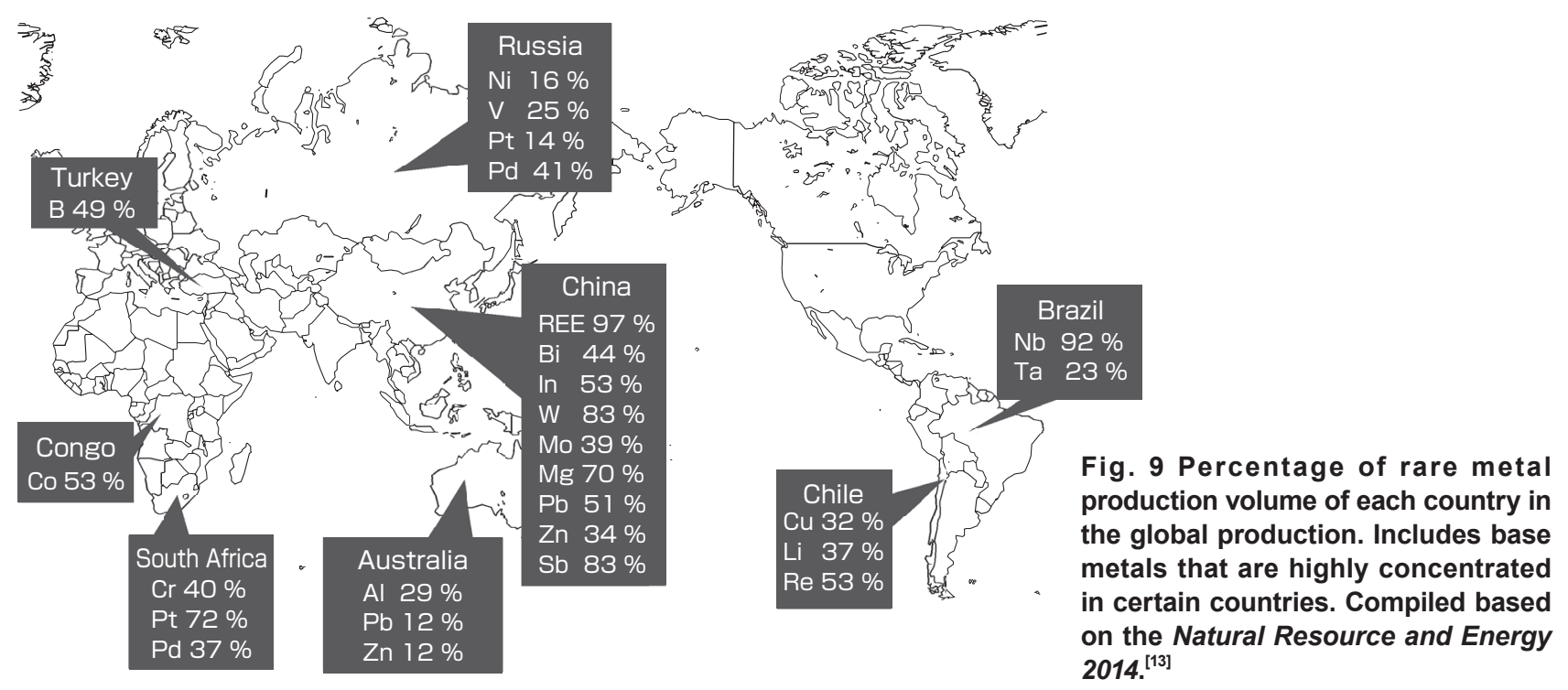

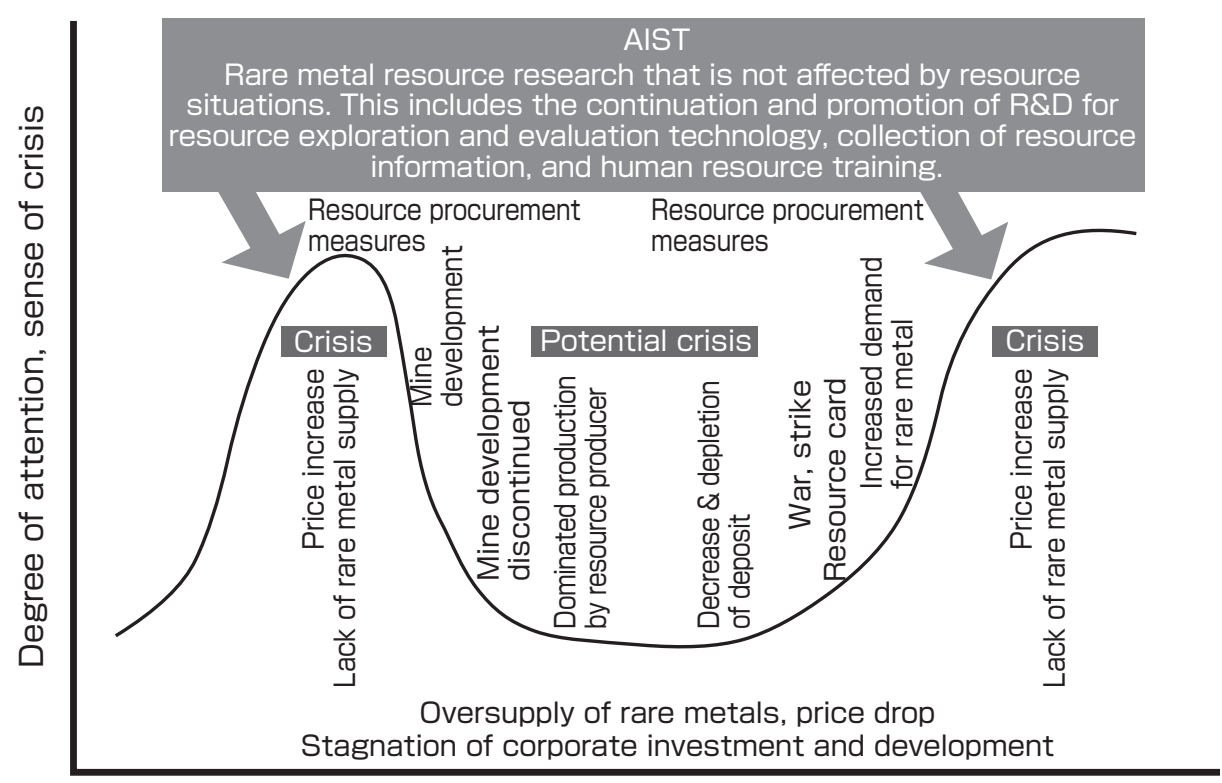

Time
Fig. 10 Conceptual diagram of full-scale research in the rare metal resource research 


\section{References}

[1] Ministry of Economy, Trade and Industry: Rare earth taisaku (Measures for rare earths), http://www.meti.go.jp/ policy/nonferrous_metal/rareearth/index.html, accessed 2015-01-05 (in Japanese).

[2] Ministry of Economy, Trade and Industry: Rare metal kakuho senryaku (Strategy for procurement of rare metals) (2009) (in Japanese).

[3] M. Nakamura: Rare metal, AIST Today, 8 (5), 10-11(2008) (in Japanese).

[4] International Atomic Energy Agency (IAEA): Management of NORM Residues, IAEA-TECDOC-1712 (2013).

[5] SURE Consortium: https://unit.aist.go.jp/emtech-ri/sure/ cons.html, accessed 2015-08-20 (in Japanese).

[6] T. Takagi: Rare metal shigen bunseki senko shiken shisetsu no seibi (Preparation of the facilities for analysis and mineral processing test of rare metal resources), AIST Today, 13 (5), 22 (2013) (in Japanese).

[7] Y. Kon and T. Takagi: Laser ko o riyo shita rare earth koseki no kagaku bunseki (Chemical analysis of rare earth ore using laser), AIST Today, 11 (1), 23 (2011) (in Japanese).

[8] Y. Kon, H. Murakami, T. Takagi and Y. Watanabe: The development of whole rock analysis of major and trace elements in XRF glass beads by fsLA-ICPMS in GSJ geochemical reference samples, Geochemical Journal, 45 (5), 387-416 (2011).

[9] U.S. Geological Survey: Mineral Commodity Summaries, http://minerals.usgs.gov/minerals/pubs/mcs/, accessed 201501-05.

[10] G. J. Orris and R. I. Grauch: Rare Earth Element Mines, Deposits, and Occurrences: U.S. Geological Survey OpenFile Report 02-189 (2002).

[11] S. Morimoto and Y. Seo: Proposal of method for evaluating measures to reduce domestic rare earth demand, Journal of Japan Society of Energy and Resources, 34 (6), 10-17 (2013) (in Japanese).

[12] Y. Seo and S. Morimoto: Comparison of dysprosium security strategies in Japan for 2010-2030, Resources Policy, 39 (C), 15-20 (2014).

[13] Shigen Energy Nenkan Editorial Board (ed.): Shigen Energy Nenkan 2014 (Natural Resource and Energy 2014), Tsusan Shiryo Shuppankai, 783 (2014) (in Japanese).

\section{Author}

\section{Tetsuichi TAKAGI}

Graduated from the Department of Geology, Faculty of Science, Shimane University in 1986. Completed the courses at the Graduate School of Science and Technology, Okayama University in 1992. Doctor (Science). Postdoctoral Fellow, Japan Society for the Promotion of Science. Joined the Geological Survey of Japan, Agency

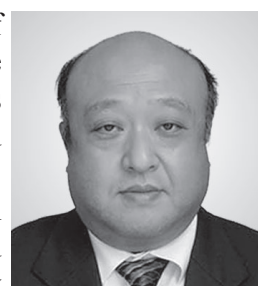
of Industrial Science and Technology in 1994, and engaged in the research for nonmetal mineral resources. Engaged in the research of geological disposal of high-level radioactive wastes at the Research Center for Deep Geological Environments, AIST from 2001 to 2006. Engaged in the research of rare metal resources at the Institute for Geo-Resources and Environment, AIST from 2007. Group Leader, Mineral Resources Research Group, GREEN, AIST from 2009. In charge of the adjustment and supervision of overall rare metal resource research.

\section{Discussions with Reviewers}

\section{Overall}

Comment (Yusaku Yano, Research Planning Division, Geological Survey of Japan, AIST; Keizo Kobayashi, Structural Materials Research Institute, Department of Materials and Chemistry, AIST)

METI placed great expectations on the Mineral Resources Research Group to which the author belonged, for the preparation of geological information needed to ensure stable supply of rare metal resources for Japan, and the Group has lived up to the expectations. The Group was expected to discover prospective deposits, prepare a base for processing tests, and construct a database. Research cooperation with many overseas geological surveys was carried out, and challenges were taken in regions such as South Africa that was remote and rife with difficulties. The author led and trained the Mineral Resources Research Group, and stood at the frontline of survey and negotiations. It is very valuable to place in Synthesiology this paper that describes the processes of survey, analysis and information, and provides an overview of rare metal resource research, particularly of rare earths. R\&D at AIST toward resource development, collaboration with resource-producing countries, and a joint research framework with partner organizations are described with actual examples. A case study is presented for the measures against the rare earth crisis that was in the news recently, and important advice is given on procuring high-risk resources to ensure sustainable development of the Japanese industry in the future. Although resource development has high risks and requires a long time, the sense of crisis felt in the industry demand-supply and the international situation is not constant. This paper clearly shows the significance of continuing resource research on a longterm basis not only when the crisis is apparent, but also when it is latent.

\section{Rare metal and rare earth}

\section{Comment (Yusaku Yano, Keizo Koyabashi)}

The general readers have difficulty separating rare metals and rare earths. Since Synthesiology is not a journal for mineral resource specialists, can you state the definitions for rare metals and rare earths, and your thoughts on how the terms are used? Answer (Tetsuichi Takagi)

The explanations of rare earths and rare metals were added at the beginning of this paper. In Japan, 31 metals are designated by METI as rare metals. They are separated from other metal resources, and measures are taken to ensure stable supply. Rare earth elements are handled as one of the metals among the rare metals, but, in practice, it is a general term for 17 metals including 15 lanthanide elements plus scandium (Sc) and yttrium (Y).

\section{Resource research within the total effort by AIST for rare metals and rare earths Question \& Comment (Keizo Kobayashi)}

I think AIST is working comprehensively on recycling, alternative material development, and usage saving technologies, not just resource development, as the measures for rare metals and rare earths. Also, I think you are spending effort (comprehensive and strategic) that is unique to AIST while considering the demand-supply balance of rare resources. From the perspective of the concept of full-scale research, I think there is an optimal technology with the industrial scenario in mind for each rare resource, but are rare earths the rare resources for which the resource development can be done most effectively? I think it will be more understandable if you describe how rare earth resource development is the most effective measure (considering the 
urgency and the realizability of alternatives), while showing us the comprehensive effort by AIST.

\section{Answer (Tetsuichi Takagi)}

I introduced the rare metal research at AIST in Subchapter 2.1. The research of rare metals can be roughly divided into materials science and earth science. In the former, the objective is the R\&D for high-performance materials using rare metals, reduction of rare metal use, alternative materials, and recycling. On the other hand, in the latter, the objective is the exploration and evaluation of rare metal resources (the development of mineral processing and refining technologies span across both fields). Since AIST engages in comprehensive research of rare metals, the rare metal task force was set up in 2006, and research was the conducted in materials science and earth science as two wheels of a car.

Rare earths are one group of the elements where resource development is the most effective measure. The reason is its small consumption volume. For example, only a few hundred tons of dysprosium (a kind of rare earth element) that is essential in increasing the heat resistance of high-performance magnets is consumed annually in Japan. However, during the rare earth crisis, it became very difficult to obtain as the price skyrocketed, since almost all dysprosium was produced in the southern part of China. If a mine that produces dysprosium is developed outside of China, even if it can produce only a fraction of the consumed volume, the price increase can be controlled as the market principle starts to function. Also, since the mining facility can be small in scale, the production can be started quickly. For the same rare metals, the effect of resource development does not become apparent in a short-term period for the elements with relatively large consumption volume (such as nickel and tungsten), and it is necessary to comprehensively and concurrently promote the development of alternative materials and recycling technology.

\section{Role of AIST in rare metal resource research and full- scale research \\ Question \& Comment (Keizo Kobayashi)}

You describe the position of AIST in resource development, the relationship with JOGMEC, and the relationship with resource-producing countries (their geological surveys), but it is a bit difficult to understand the roles of the related organizations in the resource development in the resource-producing countries. I think the measures taken are different for each country in doing resource development, but if you could describe the players' roles, I think things would become clearer in the framework of fullscale research.

\section{Answer (Tetsuichi Takagi)}

The roles of each player were described in Subchapter 3.2. In many cases, a single company or an official geological survey (AIST) engages in the phases of discovery of mineral occurrences, confirmation of ore deposits, and reconnaissance surveys. For the specific investigation phase, that is, drilling and geophysical exploration phase, the normal practice is for JOGMEC to do it alone or jointly with private companies, and then turn it over entirely to the private companies at an appropriate stage. The main developing company draws the specific development plan for the mine, conducts the environmental impact evaluation, and constructs the infrastructure, and the mine is opened only after all these phases. In the case of rare metal resources with high development risks, support by JOGMEC or JBIC may be necessary after the mine starts operation.

\section{Question \& Comment (Yusaku Yano)}

What full-scale research is in rare metal resource research and how AIST contribute in overcoming the "valley of death" are the heart of this paper. Therefore, can you discuss them thoroughly? Answer (Tetsuichi Takagi)

Seen from the perspective of rare metal resource (mine) development, in reality, the role of AIST is limited. There is a large organization called JOGMEC under METI, and the mining companies have their R\&D divisions. Therefore, writing the scenario where AIST leads the way to overcome the "valley of death" in rare metal resource development will be overrating AIST. In this paper, we presented the concept of riding the wave of demand-supply for rare metals through the contiguous R\&D at AIST. In Japan today, AIST is the only research institution that is capable of continuous and systematic information collection, survey research, and human resource training for rare metal and rare earth resources. The execution of $\mathrm{R} \& \mathrm{D}$ with medium- to long-term vision that is not affected by resource demands is the role AIST must take in full-scale research (Fig. 10). In preparation for the reaction against the lowered resource prices that will certainly happen in the future, AIST must be responsible in executing full-scale research.

The collaboration between AIST and the research institutions of resource-producing countries is an important pillar in executing full-scale research. There are many rare metal resources for which the international market has not been formed sufficiently, and because they are often targets of speculation, the reserve and grade of ores are often exaggerated in the disclosed information. To obtain accurate information, information gathering and joint survey with the official geological institution (geological survey) of the resource-producing country is necessary. AIST is a member of the International Consortium of Geological Surveys (ICOGS), and has built the cooperative relationship with geological surveys of major countries over the years. We were able to execute quick resource evaluation with South Africa, Mongolia, USA, and others during the rare earth crisis because of this cooperative relationship. We shall further promote collaboration with the geological surveys of resource-producing countries in the future. 